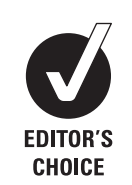

'Gastroenterology Programme, School of Postgraduate Medicine, Yorkshire and the Humber Postgraduate Deanery, Leeds, UK 2Department of Gastroenterology, Hull and East Yorkshire Hospitals NHS Trust, Hull, UK

${ }^{3}$ Royal Liverpool Hospital and University of Liverpool, Liverpool, UK

${ }^{4}$ Faculty of Medicine \& Health Sciences, Queen's Medical Centre, University Hospital, Nottingham, UK

${ }^{5}$ Clinical Hepatology, Division of Infection, Inflammation and Immunity, Faculty of Medicine, University of Southampton, Southampton, UK

\section{Correspondence to}

Dr Mounes Dakkak, Department of Gastroenterology, Hull Royal Infirmary, Hull and East Yorkshire Hospitals NHS Trust, Anlaby Road, Hull HU3 2JZ, UK; mounes.dakkak@hey.nhs.uk

Recieved 11 September 2011 Accepted 20 September 2011 Published Online First 27 October 2011

\title{
A drunk and disorderly country: a nationwide cross-sectional survey of alcohol use and misuse in Great Britain
}

\section{G Craig, ${ }^{1}$ M Dakkak, ${ }^{2}$ I T Gilmore, ${ }^{3}$ C J Hawkey, ${ }^{4}$ J M Rhodes, ${ }^{3}$ N Sheron ${ }^{5}$; the British Society of Gastroenterology}

cheap on-trade alcohol products seem likely to bring major public health benefits.

\section{Introduction}

Current UK government guidelines recommend that men should not regularly drink more than 3-4 units of alcohol a day and women should not regularly drink more than 2-3 units of alcohol a day. ${ }^{1}$ Despite recent short-term falls in alcohol consumption the prevalence of hazardous drinking (>21/14 units/ week for men/women, respectively) remains high, with $25 \%$ of men and $18 \%$ of women drinking at or above these weekly levels. ${ }^{2}$ Alcohol abuse is directly associated with cirrhosis, epilepsy, pancreatitis, dementia and foetal abnormalities and contributes to a wide range of chronic conditions, including coronary artery disease, stroke and many cancers such as oesophagus, colon, breast and liver. ${ }^{3}$ Alcohol intoxication is associated with harm from acute events such as road traffic accidents, fires, drowning, assault and child abuse. The direct burden of alcohol-related ill health in the United Kingdom is estimated to cost the National Health Service $£ 3.0$ billion/year (2006-7 prices), ${ }^{4}$ while the total costs of alcohol abuse in England (including personal loss of income and other human costs, costs to employers and public service costs) have been estimated at $£ 55.1$ billion/year. ${ }^{5}$

Information on alcohol consumption is currently collated from people living in private households in Great Britain as part of the General Lifestyle Survey (GLS), an annual survey which includes questions
This paper is freely available online under the BMJ Journals unlocked scheme, see http:// fg.bmj.com/info/unlocked.dtl
Conclusions Alcohol abuse remains common across all socioeconomic strata and geographical areas of Great Britain. Minimum pricing strategies and interventions that target 
on the average weekly alcohol consumption and maximum amount drunk on any 1 day during the previous 7 days. ${ }^{6}$ However, the GLS does not explore any of the deleterious effects of alcohol abuse upon wider society such as violence, accidents, or loss of workplace productivity. The British Society of Gastroenterology (BSG) therefore commissioned an independent survey of drinking behaviours and attitudes among the general public with the aims of examining the prevalence and detrimental social effects of alcohol abuse and exploring predictive factors for excessive alcohol consumption and subsequent personal injury.

\section{Methods}

This was a cross-sectional online survey commissioned by the BSG and administered by YouGov plc from a representative panel of $300000+$ individuals who had previously agreed to take part in surveys. An email was sent to panellists selected at random from the survey panel, inviting them to take part in the survey and providing a link to the survey. The responding sample of 2221 (48\% male) adults aged $\geq 18$, was weighted to the Great British population to provide a representative reporting sample. The voluntary survey was anonymous and was conducted during 6-8 December 2010. Associations between categorical variables were analysed by $\chi^{2}$ tests, with a $\mathrm{p}$ value of $<0.05$ considered statistically significant. Stepwise multivariate logistic regression was used to determine predictive factors for excess alcohol consumption and subsequent alcoholrelated self-harm. Only variables with a univariate $\mathrm{p}<0.10$ were included in the multivariate analysis.

\section{Results}

\section{Pervasive impact of alcohol excess across Great Britain}

The demographics and overall drinking habits of the study population are outlined in table 1 . Overall, $86 \%$ of respondents drank alcohol, with 52\% drinking at least once a week and 15\% drinking four times a week or more. It was common for people to drink at least weekly (48-53\%) throughout Great Britain, with no significant regional variations. London had a greater proportion of non-drinkers (19\%) than the rest of Great Britain $\left(12 \%, \chi^{2}=9.3, p=0.004\right)$. Excessive drinking (at least four drinks/day) on drinking days was commonest in Wales (48\%) and Scotland (46\%), compared with $39 \%$ in England. The North East of England recorded the highest proportion of heavy daily drinkers (53\%), compared with $41 \%$ in the Midlands, $38 \%$ in London and $31 \%$ in the East of England. Similar findings were noted when drinkers were asked how frequently they became drunk; becoming drunk at least twice a month was most common in Wales (19\%), Scotland (17\%) and the North (17\%) and least common in the East of England (9\%). A total of $43 \%$ of respondents knew at least one or two people whom they felt drank to excess, while $12 \%$ had at least one family member whom they felt had an alcohol problem or dependency, and 4\% stated that at least one family member had sustained liver injury due to alcohol. These findings were similar across socioeconomic strata and showed little geographical variation. Eighteen per cent of interviewees knew a family member or friend who had injured themselves while drunk, while $7 \%$ knew a family member or friend who had injured others. Twelve per cent knew a family member or friend who had been in trouble with the police through drinking and $21 \%$ knew someone who had driven an automobile while over the limit.

\section{Patterns of drinking and age}

Young people (aged 18-24) drank less often than older people, but were more likely to drink heavily on those days when they did drink (figure 1). The survey identified a subset of people at all ages who drank very heavily ( $>40$ units/week) and these heavy drinkers were significantly more likely to suffer alcohol-related harm than less heavy drinkers (figure 2). Young people mainly drank when out in pubs and clubs (39\%), but strikingly, 30\% of young people reported 'preloading'- that is, drinking cheap supermarket alcohol at home at the start of the evening before going out.

Table 1 Frequency of alcohol consumption and prevalence of alcohol-related harms among survey population

\begin{tabular}{|c|c|c|}
\hline Variable (n) & Frequency/prevalence & $\%$ \\
\hline \multirow{6}{*}{$\begin{array}{l}\text { Frequency } \\
\text { of alcohol } \\
\text { consumption } \\
\text { (2221) }\end{array}$} & Never & 13 \\
\hline & Once/month or less & 19 \\
\hline & 2-4 times/month & 15 \\
\hline & Once/week & 14 \\
\hline & 2-3 times/week & 23 \\
\hline & 4 times/week or more & 15 \\
\hline \multirow{5}{*}{$\begin{array}{l}\text { Number of drinks } \\
\text { consumed on a } \\
\text { typical drinking } \\
\text { day (1922) }\end{array}$} & $1-3$ & 57 \\
\hline & $4-6$ & 23 \\
\hline & $7-9$ & 10 \\
\hline & $10-12$ & 5 \\
\hline & $\geq 13$ & 2 \\
\hline \multirow{6}{*}{$\begin{array}{l}\text { Frequency of } \\
\text { becoming drunk } \\
\text { (1922) }\end{array}$} & Never & 49 \\
\hline & Once/month or less & 34 \\
\hline & 2-4 times/month & 7 \\
\hline & Once/week & 5 \\
\hline & 2-3 times/week & 2 \\
\hline & 4 times/week or more & 1 \\
\hline \multirow{10}{*}{$\begin{array}{l}\text { Prevalence of } \\
\text { alcohol-related } \\
\text { self harm (2221) }\end{array}$} & Self-injury while drunk & 14 \\
\hline & Injured someone else while drunk & 2 \\
\hline & Taken time off work owing to alcohol & 9 \\
\hline & Driven while over the legal alcohol limit & 7 \\
\hline & $\begin{array}{l}\text { Unintentionally caused or become pregnant } \\
\text { when drunk }\end{array}$ & 1 \\
\hline & Been in trouble with police through alcohol & 3 \\
\hline & Been taken to A\&E owing to alcohol & 2 \\
\hline & $\begin{array}{l}\text { Had a relationship breakdown partly due to } \\
\text { alcohol }\end{array}$ & 3 \\
\hline & $\begin{array}{l}\text { Been involved in domestic abuse because } \\
\text { of alcohol }\end{array}$ & 3 \\
\hline & None of these & 65 \\
\hline
\end{tabular}


Compared with 18-24 year olds, respondents aged $>54$ years also drank more frequently at home (49\% vs $\left.12 \%, \chi^{2}=114.1, \mathrm{p}<0.001\right)$, in association with a meal $\left(45 \%\right.$ vs $\left.18 \%, \chi^{2}=61.7, \mathrm{p}<0.001\right)$ and were less likely to drink in company ( $36 \%$ vs $60 \%, \chi^{2}=46.5$, $\mathrm{p}<0.001)$. While the majority $(73 \%)$ of these older drinkers drink within government daily recommended limits, $25 \%$ regularly drink to excess, with $8 \%$ drinking seven or more drinks on a typical drinking day. Despite this, most older drinkers denied becoming regularly drunk; with $81 \%$ stating that they never got drunk and only $2 \%$ reporting becoming drunk on two or more occasions a month.

A

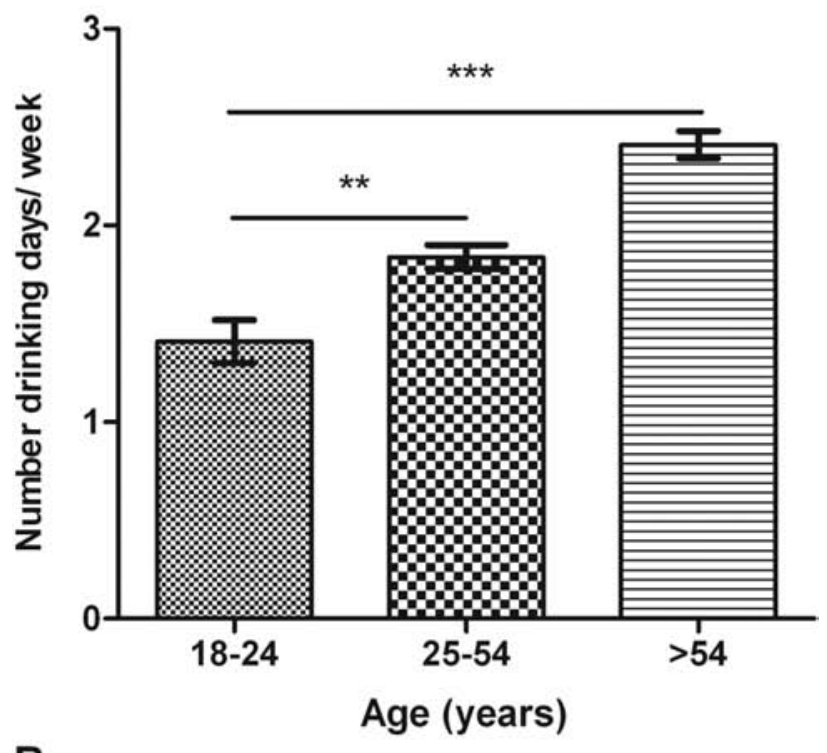

B

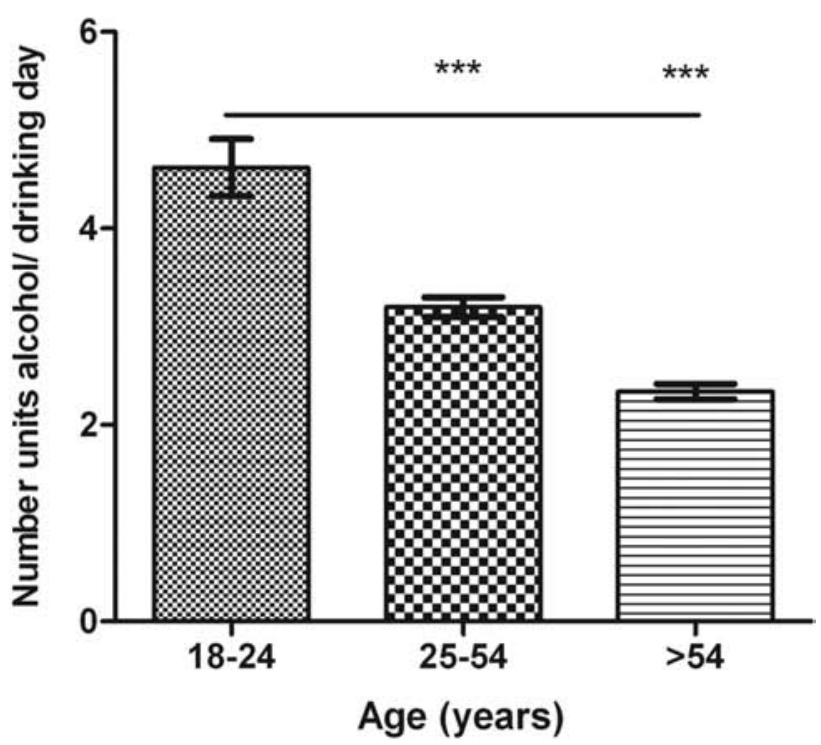

Figure 1 Young people drink significantly less frequently than older people (A), but drink significantly more on each drinking day (panel B). Data are presented as mean \pm SEM. ${ }^{*} p<0.01$; $* * * p<0.001$ analysis of variance with Bonferroni correction.
Drink driving, personal dysfunctional behaviours and loss of productivity

Overall, $7 \%$ of respondents self-reported driving while they considered themselves to be over the legal alcohol limit. This was more common among older (aged $>54)$ drinkers $(9 \%)$ compared with $6 \%\left(\chi^{2}=2.4, p=0.12\right)$ of all younger (aged $<54$ ) drinkers. Drink-driving was also significantly more common in men than in women $\left(11 \%\right.$ vs $\left.3 \%, \chi^{2}=54.9, p<0.001\right)$ and was more frequently reported by higher socioeconomic classes (ABC1) than respondents in classes C2DE (9\% vs 6\%, $\left.\chi^{2}=7.0, p=0.008\right)$.

Thirty six per cent of 18-24 year olds get drunk at least 2-4 times a month, with $27 \%$ having injured themselves while drunk and $4 \%$ having injured someone else while drunk. One per cent of all respondents reported having unintentionally caused a pregnancy or become pregnant while drunk, with identical reported rates across gender and social strata. Increasing average weekly alcohol consumption, age $<55$ years, male gender, never having been married and being in full-time employment were all independently associated with a history of alcohol-related selfharm (table 2).

Three per cent of those surveyed admitted to going to work feeling unwell as a result of alcohol at least twice a month and this was more common among young people $(10 \%)$, than for all older drinkers $(2 \%$; $\left.\chi^{2}=53.4, p<0.001\right)$. Nine per cent of all interviewees and $10 \%$ of all current workers had taken time off owing to the effects of alcohol, yet only $1 \%$ of all workers had ever received a reprimand at work due to the after effects of alcohol and only $1 \%$ could recall receiving health advice at work about alcohol.

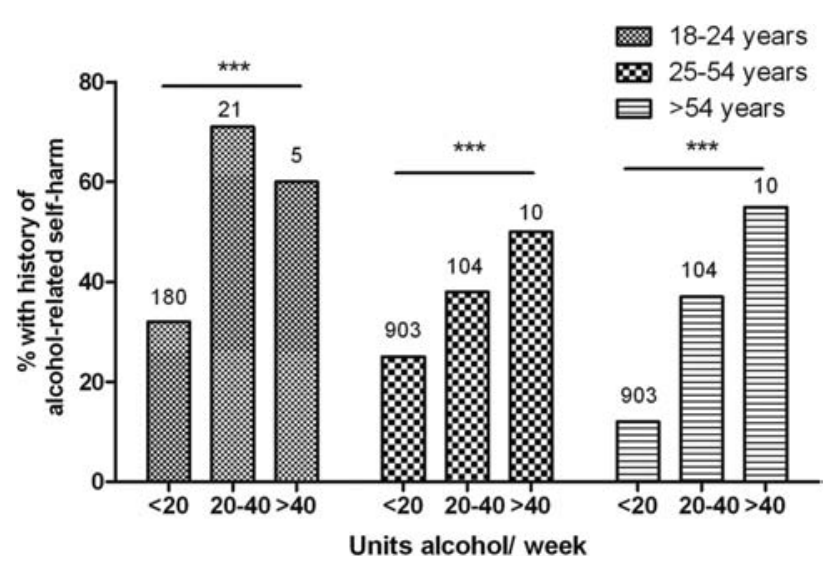

Figure 2 The prevalence of alcohol-related self-harm is strongly associated with increasing average weekly alcohol consumption. Self-harm was defined as the sum of the following alcohol-related harms: caused injury to self; caused injury to others; trouble with police; emergency department attendance; unwanted pregnancy; relationship breakdown; domestic violence; alcohol dependency. Numbers above each column represent the weighted numbers of respondents at risk for each age group/pattern of alcohol consumption. $* * * p<0.001, \chi^{2}$ test for trend. 
Table 2 Factors predictive of alcohol-related self-harm

\begin{tabular}{|c|c|c|c|c|}
\hline Variable & $\begin{array}{l}\text { Univariate OR } \\
(95 \% \mathrm{Cl})\end{array}$ & p Value & $\begin{array}{l}\text { Multivariate OR } \\
(95 \% \mathrm{CI})\end{array}$ & $\mathrm{p}$ Value \\
\hline \multicolumn{5}{|l|}{ Age (years) } \\
\hline $18-24$ & 3.09 (2.22 to 4.30$)$ & $<0.001$ & 1.94 (1.19 to 3.16$)$ & 0.008 \\
\hline $25-54$ & 1.94 (1.56 to 2.42$)$ & $<0.001$ & 1.62 (1.23 to 2.14$)$ & 0.001 \\
\hline$>54$ & 1.00 & - & 1.00 & - \\
\hline Socioeconomic class $C 2 D E$ versus $A B C 1$ & $1.11(0.91$ to 1.36$)$ & 0.304 & NA & \\
\hline Male gender & 1.57 (1.29 to 1.92$)$ & $<0.001$ & 1.34 (1.07 to 1.67$)$ & 0.010 \\
\hline \multicolumn{5}{|l|}{ Employment status } \\
\hline Student & 3.29 (2.08 to 5.19$)$ & $<0.001$ & $1.35(0.73$ to 2.50$)$ & 0.337 \\
\hline Part-time employment & $1.36(0.97$ to 1.90$)$ & 0.072 & 1.28 (0.89 to 1.84$)$ & 0.187 \\
\hline Full-time employment & 2.09 (1.64 to 2.66$)$ & $<0.001$ & $1.40(1.04$ to 1.88$)$ & 0.026 \\
\hline Not in employment & 1.00 & - & 1.00 & - \\
\hline Never married & 2.30 (1.84 to 2.87$)$ & $<0.001$ & 1.73 (1.31 to 2.29$)$ & $<0.001$ \\
\hline $\begin{array}{l}\text { Weekly alcohol consumption (for each } \\
\text { additional unit of alcohol) }\end{array}$ & 1.04 (1.03 to 1.05$)$ & $<0.001$ & 1.04 (1.03 to 1.04$)$ & $<0.001$ \\
\hline
\end{tabular}

Self-harm was defined as the sum of the following alcohol-related harms: caused injury to self; caused injury to others; trouble with police; emergency department attendance; unwanted pregnancy; relationship breakdown; domestic violence; alcohol dependency.

Reference categories (RR 1.00): middle class, married, retired, female aged $>55$.

NA, not applicable.

Table 3 Factors predictive of heavy drinking (> 40 units/week)

\begin{tabular}{|c|c|c|c|c|}
\hline Variable & $\begin{array}{l}\text { Univariate OR } \\
(95 \% \mathrm{CI})\end{array}$ & p Value & $\begin{array}{l}\text { Multivariate OR } \\
(95 \% \mathrm{CI})\end{array}$ & p Value \\
\hline \multicolumn{5}{|l|}{ Age } \\
\hline $18-24$ & 2.07 (1.07 to 4.04$)$ & 0.030 & $1.73(0.74$ to 4.08$)$ & 0.209 \\
\hline $25-54$ & $0.85(0.51$ to 1.40$)$ & 0.520 & $0.80(0.47$ to 1.37$)$ & 0.424 \\
\hline$>54$ & 1.00 & - & 1.00 & - \\
\hline Socioeconomic class $C 2 D E$ versus $A B C 1$ & $0.93(0.59$ to 1.48$)$ & 0.764 & NA & \\
\hline Male gender & 2.98 (1.79 to 4.96$)$ & $<0.001$ & $3.05(1.82$ to 5.10$)$ & $<0.001$ \\
\hline \multicolumn{5}{|l|}{ Employment status } \\
\hline Student & $2.09(0.83$ to 5.25$)$ & 0.116 & \multirow{4}{*}{ NA } & \\
\hline Part-time & $0.53(0.22$ to 1.30$)$ & 0.167 & & \\
\hline Full-time & 1.14 (0.68 to 1.89$)$ & 0.626 & & \\
\hline Not in employment & 1.00 & - & & \\
\hline Never married & $1.77(1.08$ to 2.90$)$ & 0.025 & $1.42(0.75$ to 2.69$)$ & 0.290 \\
\hline
\end{tabular}

Reference categories (RR 1.00): middle class, married, retired, female aged $>55$.

NA, not applicable.

\section{Gender effects}

Men (88\%) were significantly more likely to drink than women $\left(82 \%, \chi^{2}=15.5, \mathrm{p}<0.001\right)$, with $19 \%$ of men versus $11 \%$ of women $\left(\chi^{2}=28.4, \mathrm{p}<0.001\right)$ drinking $\geq 4$ times/week. Multivariate logistic regression identified male gender as independently predictive of very heavy drinking ( $>40$ units/week) (table 3). Men were more likely than women to exceed current recommended daily limits on a typical drinking day $(50 \%$ vs $30 \%, \chi^{2}=92.3, p<0.001$ ), with $11 \%$ of men drinking $\geq 10$ drinks on the same day compared with $4 \%$ of women $\left(\chi^{2}=34.8, \mathrm{p}<0.001\right)$. Men were less likely than women to consume alcohol with food $(27 \%$ vs $34 \%$, $\left.\chi^{2}=12.8, p<0.001\right)$, but instead tended to drink mainly when out in pubs and clubs ( $30 \%$ vs $22 \%, \chi^{2}=18.6$, $\mathrm{p}<0.001)$. Men $(19 \%)$ were more likely than women $\left(8 \%, \chi^{2}=59.0, p<0.001\right)$ to get drunk (ie, physically or mentally impaired) on at least 2-4 occasions a month and were more likely to have injured themselves or others while drunk ( $21 \%$ vs $\left.13 \%, \chi^{2}=25.5, \mathrm{p}<0.001\right)$. Men were also more likely to have taken time off work owing to alcohol consumption $\left(12 \%\right.$ vs $7 \%, \chi^{2}=16.2$, $\mathrm{p}<0.001$ ), to have driven over the legal alcohol limit $\left(11 \%\right.$ vs $\left.3 \%, \chi^{2}=54.9, \mathrm{p}<0.001\right)$ and to have been in trouble with the police $\left(5 \%\right.$ vs $\left.1 \%, \chi^{2}=30.2, \mathrm{p}<0.001\right)$ as a result of alcohol. Men were also more likely ( $5 \%$ vs $\left.2 \%, \chi^{2}=13.9, \mathrm{p}<0.001\right)$ to report dependency on, or addiction to, alcohol than women (table 4).

\section{Employment and socioeconomic status}

Respondents in regular employment (full-time or parttime) were more likely to drink $\geq 4$ times/week compared 
Table 4 Univariate analysis of gender differences in alcohol-associated drinking patterns and antisocial behaviour

\begin{tabular}{lllllll}
\hline Variable & Male (\%) & $\mathbf{N}^{*}$ & Female (\%) & $\mathbf{N}^{*}$ & $\chi^{\mathbf{2}}$ & p \\
\hline Drink alcohol $\geq 1$ /week & 57 & 1066 & 47 & 1155 & 22.3 & $<0.001$ \\
Drink alcohol $\geq 4$ /week & 19 & 1066 & 11 & 1155 & 28.4 & $<0.001$ \\
$\begin{array}{l}\text { Drink } \geq 4 \text { drinks on a typical drinking day } \\
\text { Become drunk at least twice/month }\end{array}$ & 50 & 961 & 30 & 962 & 92.3 & $<0.001$ \\
$\begin{array}{l}\text { Sustained personal injury while drunk } \\
\begin{array}{l}\text { Taken time off work owing to after-effects } \\
\text { of alcohol }\end{array}\end{array}$ & 19 & 961 & 8 & 962 & 59.0 & $<0.001$ \\
$\begin{array}{l}\text { Previously driven while over the drink-drive } \\
\text { limit }\end{array}$ & 11 & 1066 & 13 & 1155 & 25.5 & $<0.001$ \\
$\begin{array}{l}\text { Previously been in trouble with police due } \\
\text { to alcohol }\end{array}$ & 5 & 1066 & 7 & 1155 & 16.2 & $<0.001$ \\
$\begin{array}{l}\text { Been dependent on, or addicted to, alcohol } \\
\text { to some extent }\end{array}$ & 5 & 1066 & 1 & 1155 & 54.9 & $<0.001$ \\
\hline
\end{tabular}

*The responding sample was weighted to the Great British population to provide a representative reporting sample.

Table 5 Univariate analysis of differences in alcohol-associated drinking patterns and antisocial behaviours according to societal class

\begin{tabular}{|c|c|c|c|c|c|c|}
\hline Variable & $\begin{array}{l}\text { Social class } \\
\text { ABC1 }(\%)\end{array}$ & $\mathrm{N}^{*}$ & $\begin{array}{l}\text { Social class } \\
\text { C2DE (\%) }\end{array}$ & $N^{*}$ & $\chi^{2}$ & p Value \\
\hline Drink alcohol $\geq 1 /$ week & 56 & 1222 & 47 & 999 & 17.5 & $<0.001$ \\
\hline Drink alcohol $\geq 4 /$ week & 18 & 1222 & 11 & 999 & 21.2 & $<0.001$ \\
\hline Drink alcohol mainly with meals & 34 & 1093 & 25 & 830 & 20.9 & $<0.001$ \\
\hline Drink $\geq 4$ drinks on a typical drinking day & 38 & 1093 & 42 & 830 & 3.8 & 0.060 \\
\hline $\begin{array}{l}\text { Influenced by lowest priced drinks while } \\
\text { buying alcohol }\end{array}$ & 18 & 1093 & 24 & 830 & 10.2 & 0.002 \\
\hline Become drunk at least twice/month & 13 & 1093 & 16 & 830 & 4.0 & 0.045 \\
\hline Sustained personal injury while drunk & 15 & 1222 & 14 & 999 & 0.4 & 0.523 \\
\hline $\begin{array}{l}\text { Previously driven while over the drink- } \\
\text { drive limit }\end{array}$ & 9 & 1222 & 6 & 999 & 5.7 & 0.017 \\
\hline $\begin{array}{l}\text { Previously been in trouble with police due } \\
\text { to alcohol }\end{array}$ & 2 & 1222 & 4 & 999 & 6.0 & 0.014 \\
\hline
\end{tabular}

*The responding sample was weighted to the Great British population to provide a representative reporting sample.

with unemployed respondents $\left(14 \%\right.$ vs $3 \%, \chi^{2}=5.7$, $\mathrm{p}=0.012$ ). There were trends towards greater proportions of employed respondents drinking to excess on typical drinking days $\left(45 \%\right.$ vs $\left.35 \%, \chi^{2}=2.2, p=0.14\right)$ and getting drunk at least twice a month $\left(16 \%\right.$ vs $9 \%, \chi^{2}=1.9$, $\mathrm{p}=0.17)$. There were no significant differences in the proportions of employed and unemployed respondents who had injured themselves while drunk ( $17 \%$ vs $18 \%$, respectively), been taken to an accident and emergency department owing to alcohol consumption (3\% vs 3\%), or driven while over the legal alcohol limit ( $8 \%$ vs $9 \%$, respectively). Respondents in higher social classes $\mathrm{ABC} 1$ ('middle class') were significantly more likely to drink alcohol $\left(88 \%\right.$ vs $\left.80 \%, \mathrm{X}^{2}=15.5, \mathrm{p}<0.001\right)$ than social classes C2DE ('working class') and were more likely to drink $\geq 4$ times/week $\left(18 \%\right.$ vs $11 \%, \chi^{2}=21.2, p<0.001$, (table 5). ABC1 classes drinkers were more likely to drink at home ( $40 \%$ vs $\left.35 \%, \chi^{2}=5.8, p=0.018\right)$, to drink with a meal $\left(34 \%\right.$ vs $\left.25 \%, \chi^{2}=20.9, p<0.001\right)$ and to drink mainly at the weekends ( $39 \%$ vs $32 \%, \chi^{2}=11.7$, $\mathrm{p}=0.001$ ) than C2DE drinkers. However, C2DE drinkers were slightly more likely to get drunk at least twice/ month $\left(16 \%\right.$ vs $\left.13 \%, \chi^{2}=4.0, p=0.045\right)$, with a tendency to drink above current recommended daily limits $\left(42 \%\right.$ vs $\left.38 \%, \chi^{2}=3.8, p=0.06\right)$ and reported a greater influence of low-priced drinks ( $24 \%$ vs $18 \%, \chi^{2}=10.2$, $\mathrm{p}=0.002)$, buy-one-get-one-free promotions $(17 \%$ vs $\left.13 \%, \chi^{2}=6.0, p=0.01\right)$ and cheap price promotions $\left(25 \%\right.$ vs $\left.22 \%, \chi^{2}=2.4, p=0.13\right)$. Similar proportions of drinkers from both social classes reported self-injurious behaviour while drunk, but middle-class drinkers were more likely to have driven while above the legal alcohol limit ( $9 \%$ vs $\left.6 \%, \chi^{2}=5.7, p=0.017\right)$, whereas workingclass drinkers were more likely to have had trouble with the police as a result of drinking $\left(4 \%\right.$ vs $2 \%, \chi^{2}=6.0$, $\mathrm{p}=0.014$ ), or to have had a relationship breakdown as a result of alcohol ( $4 \%$ vs $\left.2 \%, \chi^{2}=6.0, p=0.014\right)$.

\section{Incentives and disincentives}

Young people were heavily influenced by the effect of price, with $35 \%$ stating that drinks with the lowest price 
influenced them, compared with $21 \%$ of 25-34 year olds and just $13 \%$ of $35-44$ year olds. This youngest age group was also most influenced by cheap price promotions (33\%) compared with $22 \%$ of all older drinkers $\left(\chi^{2}=14.9, \mathrm{p}<0.001\right)$, or buy-one-get-one-free type promotions $\left(28 \%\right.$ vs $\left.13 \%, \chi^{2}=35.3, p<0.001\right)$. Young people were more likely to choose high-strength alcohol or shots in order to rapidly become drunk (13\%) compared with $4 \%$ of $25-34$ year olds and $<1 \%$ of older drinkers and tended to buy drinks thought less likely to cause a hangover $\left(15 \%\right.$ vs $\left.11 \%, \chi^{2}=3.6, p=0.06\right)$.

\section{Discussion}

This large cross-sectional survey demonstrates the widespread use and abuse of alcohol throughout Great Britain. From a representative sample of 2221 individuals, this survey reveals that $15 \%$ of people drink four times a week or more, with $40 \%$ drinking over the recommended daily limits. The survey confirms the widespread nature of 'binge' drinking among young adults, with its attendant risks of personal injury and dysfunctional illegal or abusive behaviour. Chronic alcohol abuse is particularly prevalent; among older drinkers, of whom $25 \%$ regularly drink to excess, $8 \%$ drink seven or more drinks on a typical drinking day. The effects on young people are particularly alarming-36\% of 18-24 year olds get drunk at least 2-4 times a month, $27 \%$ have injured themselves while drunk and $4 \%$ have injured someone else. Men appear to be at particularly high risk for heavy drinking independent of age, working status, or social class. The pervasive effects of this acute and chronic alcohol abuse in Great Britain are strikingly apparent from this survey: $18 \%$ of those interviewed knew a family member or friend who had injured themselves while drunk, $43 \%$ knew of at least one person who drinks to excess and $12 \%$ had at least one family member in this situation. Moreover, the harmful effects of excess alcohol are seen across all socioeconomic classes.

This independent survey provides additional information on alcohol use not available from the governmental GLS or other surveys of adults' drinking behaviour. ${ }^{6}$ In particular, this study is one of the few nationwide surveys to directly question interviewees about personal dysfunctional behaviour related to alcohol. The survey population was derived from an established YouGov representative panel of adults in Great Britain and therefore is likely to represent a true picture of overall drinking patterns. However, as with all cross-sectional surveys, this study represents only a snapshot of drinking patterns and we cannot directly infer causality or examine the longitudinal impact of the increased affordability of alcohol in Britain. Surveys of this type are dependent upon the accuracy of self-reported alcohol use, which may limit the accuracy of quantities consumed; however, previous data from the British Beer and Pub Association have suggested that drinkers tend to under-report consumption and therefore alcohol-related problems may be even more widespread than reported in this study. ${ }^{2}$

This study provides further evidence of the widespread use and abuse of alcohol throughout Great Britain. Overall, $57 \%$ of men and $47 \%$ of women reported drinking at least once a week, levels which are slightly lower than those reported by the 2009 GLS, which found that $68 \%$ of men and $54 \%$ of women had drunk alcohol in the preceding week. ${ }^{2}$ This may relate to the slightly different question used in the two surveys, or may reflect a recent downward trend in overall drinking rates. We found that $13 \%$ of $18-24$ year olds and $11 \%$ of $25-54$ year olds were drinking at levels associated with increased physical ill health ( $>20$ and $>40$ units/week). This cohort of regular drinkers- the 'liver deaths' of the future-experienced more than three times as many acute harms even in the younger age groups. This is perhaps not surprising given that frequency of drinking occasions is perhaps the most important single question in the World Health Organisation risk assessment tool (AUDIT). ${ }^{7}$ This calls into question the government's controversial move from weekly to daily drinking guidelines. ${ }^{18}$ The switch from a weekly to a daily guideline proved to be a gift to the drinks industry and coincided with a sharp increase in rates of liver death. ${ }^{9}$

This study emphasises the impact and prevalence of alcohol-related antisocial behaviour, particularly among men and younger drinkers. Perhaps surprisingly, drinkers in full-time employment were also identified as at-risk for these antisocial behaviours. The results among 18-24 year olds, of whom 64\% drank excessively on drinking days and $27 \%$ had injured themselves while drunk, are particularly striking. 'Binge-drinking', defined as feeling very drunk at least once a month, occurs most commonly in 18-24 year olds and is strongly associated with crime and antisocial behaviour, with a previous study reporting offending rates of $27 \%$ in young binge-drinkers compared with $13 \%$ of other young drinkers. ${ }^{10}$ Public health policies to target drinking in this age group are therefore urgently required. While 'pre-loading' at home was common among 18-24 year olds, this survey confirms previous research showing that young people purchase alcohol mainly in licensed premises ${ }^{11}$ and suggests that young people are particularly influenced by drinking venue and atmosphere. Additionally, young drinkers are swayed by price, with $33 \%$ being influenced to drink by cheap price promotions, $35 \%$ by the drink with the lowest price and $28 \%$ by buy-one-get-onefree offers. This survey therefore supports the conclusion that policies targeting cheap on-trade alcohol products and offers, such as a $10 \%$ increase in lowprice on-trade alcohol, are likely to have the biggest influence in curbing excessive drinking among 18-24 year olds. ${ }^{11}$ The prevalence of drink-driving identified 
by this survey is also of considerable concern. A total of $7 \%$ of respondents self-reported driving while they considered themselves to be drunk and this rose to $9 \%$ of older drinkers and $9 \%$ of middle-class respondents, suggesting that drink-driving remains a significant problem in Great Britain. The implementation of random breath testing, which permits police to stop motorists who are not suspected of committing an offence, might have a sustained and significant impact upon this persistent problem. ${ }^{12}$

This survey also highlights the problem of excessive chronic drinking among older adults-over 20\% of drinkers aged $55+$ drink four or more times a week and it is likely that a substantial minority of these drinkers exceed governmental recommended limits. Interestingly, older drinkers also appear to be substantially influenced by price when buying alcohol, suggesting that pricing strategies such as raising the minimum price of a unit of alcohol to $£ 0.50$ could preferentially target this subgroup. Such minimum pricing strategies could reduce consumption by $6.9 \%$, save 2930 lives a year and save $£ 6.2$ billion in health costs over 10 years. ${ }^{13}$

On 20 May 2010 the new coalition government published their strategy to tackle the harmful use of alcohol, which included banning the sale of alcohol for less than the combined tax and duty paid on it, along with a review of alcohol taxation and pricing to tackle binge-drinking 'without unfairly penalising responsible drinkers, pubs and important local industries'. Although welcome, the impact of these policies alone upon the problem drinkers identified by this survey are likely to be limited, ${ }^{14}{ }^{15}$ and there is an urgent requirement for a review of alcohol policy independent of the alcohol industry with the aim of introducing measures to target the youthful bingedrinking, drink-driving and chronic alcohol abuse among older people highlighted by this survey. Given that the affordability of alcohol in the UK increased by $65 \%$ between 1980 and 2006, interventions which target price are likely to have the greatest public health impact.
Competing interests None.

Provenance and peer review Not commissioned; externally peer reviewed.

\section{References}

1. Department of Health. Sensible Drinking: The Report of an Interdepartmental Working Group. London: Department of Health, 1995.

2. Robinson S, Harris H, Dunstan S. Smoking and Drinking Among Adults, 2009. A Report on the 2009 General Lifestyle Survey. Newport: Office for National Statistics, 2011.

3. Rehm J, Gmel G, Sempos CT, et al. Alcohol-related morbidity and mortality. Alcohol Res Health 2003;27:39-51.

4. Balakrishnan R, Allender S, Scarborough P, et al. The burden of alcohol-related ill health in the United Kingdom. J Public Health (Oxf) 2009;31:366-73.

5. BMA Board of Science. Alcohol Misuse: Tackling the UK Epidemic. London: British Medical Association, 2008.

6. Robinson S, Bugler C. General Lifestyle Survey: Smoking and Drinking Among Adults, 2008. Newport: Office for National Statistics, 2010.

7. Saunders JB, Aasland OG, Babor TF, et al. Development of the Alcohol Use Disorders Identification Test (AUDIT): WHO Collaborative Project on Early Detection of Persons with Harmful Alcohol Consumption-II. Addiction 1993;88:791-804.

8. Edwards G. Sensible drinking. BMJ 1996;312:1.

9. Anderson P. A safe, sensible and social AHRSE: New Labour and alcohol policy. Addiction 2007;102:1515-21.

10. Matthews S, Richardson A. Findings from the 2003 Offending, Crime and Justice Survey: Alcohol-related Crime and Disorder. London: Home Office, 2005.

11. Purshouse RC, Meier PS, Brennan A, et al. Estimated effect of alcohol pricing policies on health and health economic outcomes in England: an epidemiological model. Lancet 2010;375:1355-64.

12. Henstridge J, Homel R, Mackay P. The Long-term Effects of Random Breath Testing in Four Australian States: A Time Series Analysis. Canberra: Federal Office of Road Safety, 1997.

13. Gilmore IT, Atkinson S. Evidence to drive policy on alcohol pricing. Lancet 2010;375:1322-4.

14. Coltart CE, Gilmore IT. Minimum alcohol pricing in England. BMJ 2011;342:d1063.

15. Sheron N, Hawkey C, Gilmore I. Projections of alcohol deaths-a wake-up call. Lancet 2011;377:1297-9. 